Univerzitet u Beogradu

Filološki fakultet

saravukotic1@gmail.com

\title{
INFANTILNA PERCEPCIJA SVETA U CANKAREVOM ROMANU KUĆA MARIJE POMOĆNICE
}

Ovaj rad zasnivaće se na tumačenju infantilne percepcije sveta u Cankarevom romanu Kuća Marije pomoćnice koja je interpretativno interesantna stoga jer izneverava konvencionalni horizont očekivanja. Suštinska egzistencijalna pitanja poput života, smrti, slobode, te odnosa prema drugome i drugosti propuštena su kroz vizuru deteta, te je znakovito pratiti kako se pojam dečijeg razvija u romanu. S tim u vezi važno je napomenuti I uticaj porodičnog modela na formiranje ličnosti, pri čemu se u romanu može primetiti njegovo narušavanje I niz posledica koje takvo narušavanje izaziva kod dece, aktivirajući izrazito pesimistično poimanje sveta. Tema bolesti takođe će u radu zadobiti važno mesto u cilju rasvetljavanja infantilnog pogleda na svet.

Ključne reči: infantilno, život, smrt, sloboda, bolest, porodica

Roman Kuća Marije pomoćnice izašao je 1904. godine i predstavlja važan momenat u Cankarevom stvaralaštvu iz više razloga. Svojim poetičkim osobinama roman predstavlja važan korak ka modernoj književnosti jer poklanja pažnju psihološkoj istančanosti likova i simboličkoj nadogradnji priče (Cesar 1990: 153). Takođe, svojom strukturnokompozicionom organizovanošću roman pravi otklon od tradicionalnog tipa kontinuiranog romana, pri čemu se okvirna priča Malčikinog dolaska u bolnicu razgranava u 14 paralelnih priča o bolesnim devojčicama, sagledanih iz hic et nunc trenutka romana, ali i retrospektivnim osvrtom na život devojčica pre bolnice. Ove dve poetičke odrednice Cankarevog romana tesno su povezane - retrospektivno pripovedanje o prošlosti bolesnih devojčica doprinosi njihovoj psihološkoj kristalizaciji kao i motivaciji tematsko-motivskog nivoa samog romana. Međutim, Cankarev roman sa druge strane baštini i neke od elemenata naturalističke poetike, poput motiva praroditeljskog greha i uticaja nasleđa na 
konstituisanje sudbine junaka, kao i naturalističkih opisa bolesti, što će uz religiozno-hrišćanski sloj ovog romana ponuditi moguće rešenje za tumačenje infantilne percepcije sveta u romanu.

Takođe, i osvrt na spoljašnji plan romana Kuća Marije pomoćnice svrsishodan je za tumačenje teme ovog rada. Naime, prvobitna negativna recepcija ovog Cankarevog romana koja je dovela i do njegove cenzure govori mnogo o odnosu kritike i čitalaca prema promenama koje Cankar utemeljuje pišući i objavljujući ovaj roman. Pomenute strukturne novine, kao i teme koje su umnogome od strane čitalačke publike sa početka dvadesetog veka smatrane tabu na radikalan način narušavaju konvenvionalni horizont očekivanja, što je u direktnoj vezi sa njegovom prvobitnom negativnom kritikom. Motiv bolnice koju ispunjavaju neizlečivo bolesna deca koja priželjkuju smrt i nadaju joj se svakako nije predstava koju prvo zamislimo kada pomislimo na decu. Takođe, motivi nasilja, seksualng zlostavljanja, incesta i homoseksualnih veza koji se za temu bolesne dece vezuju doveli su do toga da Cankarev roman isprva bude cenzurisan. Ovaj rad stoga će se kretati u pravcu otkrivanja sloja ideja i značenja romana koja motivišu pesimističnu viziju dečijeg odrastanja i sudbine kakva je u romanu prikazana.

\section{Od traume do uznesenja}

Nepravda koju dete doživi ureže se u mlado srce i tu ostane zauvek neizbrisana, učini da to dete rano sazri i postane ogorčeno, otvaramo silom oči da vidimo prve i nejasne senke tih strahota koje mu se kasnije razotkrivaju u svoj svojoj okrutnoj golotinji.

Ivan Cankar

Središnji deo ovog rada zasniva se na izdvajanju ključnih postupaka u Cankarevom romanu koji utiču na ostvarivanje specifične infantlne percepcije sveta. U tom smislu znakovito je isprva ostvariti određeni širi kontekst, prostorni i vremenski, koji u interpretaciji romana funkcioniše kao dodatno semantičko pojašnjavanje osnovnog idejnog sloja teksta. Naime, početak priče o bolesnim devojčicama poklapa se sa Malčikinim dolaskom u bolnicu. Na taj način, kako će se dalje u romanu ispostaviti, upravo je Malčikina priča izabrana da svojom celovitošću bude reprezent za tragičnu sudbinu deteta u prostoru kakav je u 
romanu prikazan. Čitalac ima priliku da u romanu pratu Malči od dolaska u bolnicu, preko njegog boravka u njoj, sve do prerane smrti, koja je neizbežan deo života u bolnici. Izabravši Malčikinu priču za nucleus romana, Cankar poimanje bolnice, aktera i događaja u njoj propušta kroz njenu vizuru, ostvarujući na taj način, i u fokalizatorskom smislu, specifičnu infantilnu percepciju sveta. Stoga se i prostorni okvir u koji su smeštene bolesne devijčice predočava iz Malčikine perspektive, što je izuzetno znakovito za tumačenje osnovnih ideja koje se tokom romana razvijaju. Naime, Malčikinim prolaskom kroz velika železna vrata (Цанкар 1964: 133) na samom početku romana otvaraju se vrata jednog marginalnog i od spoljašnjeg života skrajnutog, odbačenog prostora okarakterisanog kao manastir/bolnica. Već u prvim opisima taj prostor opisan je kao mračan, turoban, hladan što na psihološkom planu Malčikinog lika izaziva strah i zebnju, dok na semantičkom planu anticipira atmosferu prisutnu tokom celog romana. Dvostruko razumevanje prostora u koji je Malči stupila, istovremeno i kao manastira i kao bolnice, ima takođe svoju semantičku funkciju. Naime, devojčice koje u tom prostoru borave neizlečivo su bolesne, te u njihovom slučaju bolnica u smislu fizičkog ozdravljenja nema prevelikog značaja. Sa druge strane, karakterisanje prostora kao manastira, religioznog utočišta i nade u svetliji zagrobni život, ispostaviće se da ima velikog značaja u sudbinama ovih devojčica.

Velikim gvozdenim vratima koje se pominju na samom početku romana, na povlaščenom semantičkom mestu, anticipira se još jedna važna konotativna ravan romana. Granica koja se uspostavlja tom prilikom između života van i života unutar bolnice, prikazana na jedan konačan i nepromenljiv način, održaće se tokom celog romana i nadograđivaće se čestim razmišljanjem devojčica o toj granici, kao i epizodama sa simboličkom vrednošću. Tokom romana dolaziće neretko do preklapanja spoljašnjeg i unutrašnjeg sveta, međutim, sve vreme se jasno pocrtavaju njihove razlike i nemogućnost usaglašavanja i postizanja harmoničnog odnosa. Dakle, prostorni sloj romana ostvaruje jednu turobnu i mračnu atmosferu u kojoj, neočekivano, žive deca, pri čemu je ostvarena i jaka granica ižmeđu njih i ostatka sveta, što dalje utiče na konstituisanje motiva odbačenog deteta, karakterističnog za ovaj roman. Sa druge strane, vremenski sloj romana, iako prividno održava svoj kontinuitet posredstvom dominantne Malčikine priče, raslojava se neretkim vremenskim skokovima u prošlost, što na semantičkom planu takođe karakteriše devojčiče i motiviše njihove tragične sudbine. Na- 
ime, iz pripovedanja o prošlosti saznaje se da sve devojčice potiču iz disfunkcionalnih porodica, te da nose mnoge traume iz detinjstva, što je znakovito za interpretaciju njihove izrazito pesimistične slike sveta.

Od trenutka kada Malči stupi u lokus bolnice koji funkcioniše po specifičnim pravilima unutrašnje logike, otvara se priča o 14 devojčica, objedinjena zajedničkim motivima bolesti, smrti i nezdravog odrastanja. Na rastanku sa majkom Malči se ne ponaša kao dete i, iako je zabrinuta i strah ju je jer ulazi u nepoznai prostor, ona je ta koja teši majku i briše joj suze, što govori da su funkcije u okviru porodičnog modela iz kojeg je Malči potekla redefinisane, te da se dete ponaša kao odrasla osoba, kao roditelj i hvata se u koštac sa sada već izvesnom tragičnom sudbinom. U bolnici u kojoj je ostavljena Malči se već u prvim trenucima suočava sa smrću jer ostale devojčice za prvi kontakt sa Malči biraju da joj ispričaju kako je devojčica koja je spavala na njenom krevetu umrla. Turobnoj atmosferi doprinosi i način na koji se devojčice odnose prema smrti - njima je to svakodnevna stvar, te o smrti pričaju sa lakoćom i bez uzrujavanja. U konvencionalnom smislu razmišljanja dete predstavlja nešto što je nevino, tek rođeno i pred kim je ceo život, te smrt predstavlja nešto daleko i apstraktno. Međutim, devojčicama koje su akteri Cankarevog romana smrt je svakodnevna stvar, toliko bliska i opipljiva da postaje tragično koliko su one na smrt naviknute i sa koliko ozbiljnosti i pomirenosti je prihvataju kao takvu, neizbežnu i izvesnu. Zarobljene u bolnici bez izlaza, devojčice razumeju da je sloboda nešto o čemu mogu samo da sanjaju, da je ona njima nedostižna. Međutim, usled nedostatka slobode u njihovom teškom životu dolazi do, za dečije razmišljanje, potpuno neočekivanog paralelizma smrti i slobode, pri čemu devojčice suvereno tokom romana iznose mišljenje da je za njih jedini predeo slobode upravo smrt, te da će se nakon smrti odmoriti i spasiti. Na ovakvu predstavu života i smrti ukazuje i onirički momenat na kraju prvog dela romana pri čemu Malči sanja livadu punu cveća, sunčan dan i sebe kako trči, čime se ostvaruje jedan idealizovani predeo koji je njoj nedostižan. Ona takođe, na podsvesnom nivou sna, fizički nedostatak zbog kojeg je i dospela u bolnicu otklanja, te uspeva da slobodno trči i uživa u životu. Simbolički potencijal Malčikinog sna ukazuje na nepremostivi jaz koji postoji između njene težnje za srećnim životom i grube realnosti koja joj to ne dopušta, što dovodi do tragične slike sveta. U skladu sa izrazitim pesimističkim nabojem koji dominira romanom, neretko dolazi do poistovećivanja prostora bolnice i mrtvačnice, što takođe ukazuje na samosvest koja karakteriše devojčice i njihovo poimanje sopstvene sudbine. 
Pored oniričke, još jedan vid simbolike dodatno semantički pojašnjava infantilnu percepciju sveta u Cankarevom romanu. Naime, dve epizode sa pticama, vrapcem kanarincem, mogu se povezati na makroplanu sa univerzalnom sudbinom devojčica u bolnici (Kos 1975: 245), ali i na mikroplanu sa dve određene devojčice, Tinom i Katicom, pri čemu, postupkom paralelizma, sudbine ptica postaju reprezenti sudbine ovih dvaju devojčica. U tom smislu i animalna simbolika dodatno rasvetljava stradanje i patnje devojčica.

Tina je interesantna kao lik jer se unekoliko odvaja od drugih devojčica po svojoj želji za životom. Ona isprva žudi za onim što je izvan bolnice, za slobodom, ali je svesna da je svuda oko nje smrt i da je život nedostižan. U njenom liku prepoznajemo i želju za ljubavlju ona neprestano zamišlja sliku dvoje mladih ispod drveta na klupici koju i opredmećuje kada upozna Edvarda, brata jedne od devojčica koji im dolazi u posetu. Edvard za Tinu predstavlja sponu sa spoljašnjim svetom, deo tog sveta koji ona počinje da voli nevino i čisto, upravo onako kako je detetu i svojsvteno. Međutim, iako je Tina predstavljena kao lik kod kojeg postoje zaostaci pozitivnih vrednosti, sveopšta turobna atmosfera čiji je ona deo ne dopušta joj da ostvari svoje težnje. Na isti način kao i kod Malči, u Tininom liku sukobljavaju se predeo želje i predeo realnosti, pri čemu nužno dolazi do stradanja (Mitrović 1995: 211). Naime, Tina pokušava da se ubije, što uvodi i motiv suicida, koji je ponovo neočekivano vezan za dete i dečije. Dakle, iako se isprva može učiniti da u Tininom liku postoje pozitivne vrednosti, ona kao i ostale devojčice strada, a ključ za razumevanje neuspeha nalazi se u epizodi sa vrapcem. Vrapca Antihrista devojčice su dobile na poklon, kako bi im uneo živost i razigranost u turoban prostor. Međutim, kao i Tina, vrabac je žudeo za životom i begom iz smrti, te je neprestano udarao u zatvoreni prozor, što ga je ubilo. Slično Tini, i vrabac nailazi na nepremostivu granicu između spolja i unutra, pri čemu svaki pokušaj narušavanja te granice završava neizbežnim stradanjem onoga ko pokušava da je prevaziđe. Kao i prema Tini, devojčice su prema smrti vrapca ravnodušne, pomalo se čak i podsmevaju njegovom naivnom pokušaju da izađe iz smrti i živi (Mitrović 1995: 212).

Kao i vrabac Antihrist, kanarinac Hanzek veoma je sličan devojčicama iz više razloga. Kada ga donesu u bolnicu on je veoma uplašen, uznemiren i boji se spoljnog sveta i strahota u njemu. On uspeva da ostvari odnos sa devojčicama i počinje da im veruje upravo zato što su po prirodi slični, ali zazire od bilo kakvog prisustva spoljnog sve- 
ta koji i devojčice poimaju kao neprijateljski. Posebnu vezu kanarinac ostvaruje sa Malči, koja se prema njema ponaša prijateljski, te se među njima ostvaruje pozitivan odnos. Međutim, dolazak gostiju i roditelja u bolnicu u posetu devojčicama Hanzeka čini uznemirenim, paralisanim od straha. Otac jedne od devojčica, Katice, grub i nezgrapan prilazi kanarincu, pri čemu Hanzek kako bi pobegao leti ka zatvorenom prozoru i umire. Strah od bliske smrti koju je prepoznao u nadolazećem neprijatelju u njemu aktivira želju za životom, ali ponovo dolazi do sukoba želje i realnosti, pri čemu kanarinac strada. Katica se u ovoj situaciji poistovećuje sa kanarincem jer se seća kako je i ona mnogo puta u prošlosti zazirala od svog oca koji je nasilnik i pijanica. Na taj način se Katičin pesimistični pogled na svet motiviše traumama koje je u detinjstvu doživela u okviru porodice. Takođe, devojčice se u odnosu na goste koji dolaze iz sveta izvan bolnice postavljaju superiorno jer razumeju da je taj svet pun zlobe i strahota, te da su one od njega zaštićene. Stoga se i motiv bolesti koji je jedan od konstantnih motiva u ovom romanu može raslojiti. Naime, devojčice su fizički bolesne i pate od mnogih nedostataka, ali se spoljašnji svet prikazuje kao moralno nečist i okaljan (Cesar 1990: 154), i reprezentuje se prikazom disfunkcionalnih porodičnih modela koji su prouzrokovali devojčicama mnogo patnja kako na fizičkom tako i na emotivnom planu. Stoga se porodični sloj romana Kuća marije pomoćnice treba posebno uzeti u obzir kada se govori o infantilnoj percepciji sveta ovog romana koja je izrazito pesimistički obojena.

Porodični sloj posebno je tematizovan u petom delu romana gde se Malčina priča polifonijski raslojava na niz paralelnih slika koje analeptički govore o detinjstvu svake devojčice ponaosob i iz kojih se može iščitati da je bolest od koje devojčice pate kako na fizičkom tako i na psihološko-emotivnom planu produkt nezdrave sredine u kojoj su odrasle (Cesar 1990: 155).

U epizodama koje tematizuju odrastanje devojčica dominiraju motivi nasilja, nebrige, neprimernog ponašanja roditelja, homoseksualnosti, gladovanja, pijanstva i lošeg porodičnog uzora pri čemu se ostvaruje univerzalni disfunkcionalni porodični model, koji kao takav ne priprema devojčice za život, te one ostaju po strani od njega. One često i preziru život, podsmevaju mu se i gade upravo zato što je sve što su od života videle i iskusile bilo negativno i detetu nesvojstveno.

Tina, devojčica u čijem liku prepoznajemo elemente ljubavi i sreće, trpela je nasilje, bila je ostavljana po dva dana na djubrištu bez 
hrane gde je razvila želju za smrću koju ne poima kao nešto negativno, već naprotiv, raduje joj se i željno je iščekuje kao milu staricu koja deli poklone. U njenoj priči dominira još jedan kardinalan motiv ovog Cankarevog romana - motiv odbačenog deteta - koji je prisutan u svakoj od pojedinačnih priča devojčica. Na koncu, sve su one samim dovođenjem u bolnicu odbačene od strane svojih porodica, a onda i od celog sveta od kojeg su nepremostivo odvojene.

I pored traumatičnog detinjstva, u Tini postoje ljubav i želja za životom, međutim, njen pokušaj samoubistva nakon izneverenih čežnji pokazuje da je nemoguće otrgnuti se od sudbine. Nakon što je Edvard odbije, ona doživljava otrežnjenje i shvata da je bolesna i ružna, što kulminira suicidalnim pokušajem. Scena njenog suočenja sa sopstvenom sudbinom izrazito je potresno i naturalistički predstavljena - Tina pokušava sebe da rastrgne, zariva nokte u kožu dok joj ne krene krv. Dakle put koji je ona kao lik prešla, od trauma iz detinjstva preko pokušaja prevazilaženja trauma i odavanja životu do ponovne grube realnosti i smrti samo joj na još jedan način pokazuje da se nalazi u bezizlaznom položaju, te vodi ka želji za samouništenjem i nadi u smrt.

I šesti deo romana tematizuje porodični nemoral: govori o Lojzikinom ocu koji vara majku i na Lojzikine oči i spopada maloletnu devojčicu; o Brigitinoj majci koja vara oca i Brigitinom traumatičnom iskustvu silovanja; o Tončki koja se seća svog neprijatnog homoseksualnog iskustva iz detinjstva. Svi ovi negativni motivi koji su presudno uticali na ostvarivanje pesimističnog pogleda na svet kod devojčica dobijaju svoje moguće semantičko razrešenje u poslednjem delu romana.

Slike Božića i prazničnog rapoloženja prikazane u poslednjem delu romana prepliću se sa traumatičnim vizijama detinjstva devojčica, pri čemu se nameće motiv roditeljskog greha i negativnog porodičnog modela kao izvor šire slike života koji u totalitetu preziru. Motiv bolesti i stradanja devojčica, povezan sa roditeljskim grehom, može se stoga tumačiti u skladu sa naturalističkim nasleđem koji je u romanu prisutan još i na planu opisa fizičkih patnji devojčica usled bolesti, kao i u ideji da su tragične sudbine devojčica posledica negativnog nasleđa iz kojeg su proistekle (Mitrović 1995: 212). Atmosfera Božića iz glavnog narativa u tom smilu funkcioniše kao antiteza prizorima iz sećanja devojčica, pri čemu se motiv roditeljskog greha i dečijeg stradanja dovode u vezu posredstvom motiva žrtve. Aktivacijom hrišćanskog sloja romana postiže se, pored antitetičnosti praznične atmosfere Božića i traumatičnog detinjstva devojčica, i paralelizam motiva žrtve u liku 
Hrista i u likovima devojčica. Na isti način na koji je Hrist stradao za ljudske grehe, i devojčice pate i stradaju zbog licemerstva i grehova svojih roditelja. Takođe, eksplicitno poređenje scene iz romana kada gosti dolaze devojčicama u posetu za Božić sa dobro poznatom pričom o Hristovom rođenju ukazuje na moguće poređenje ovih dvaju narativa, pri čemu u oba slučaja grešnici dolaze da okaju svoje grehe pred nekim nevinim i čednim. $\mathrm{Na}$ isti način na koji je paralela devojčica sa vrapcem i kanarincem dodatno motivisala njihovu tragičnu sudbinu, i paralela sa Hristom na određeni način, u ključu naturalističkog iščitavanja, dodatno motiviše, ili moglo bi se reći opravdava stradanje i patnje devojčica. Na taj način se dominantni narativ romana aluzijama i simboličnim pričama idejno širi i ulančava u koherentan semantički sistem. Hrišćanski religijski nivo romana aktivira se već i samim naslovom koji predstavlja naziv za manastir pretvoren u bolnicu u kojoj se devojčice, pored suočenja sa svojim fizičkim bolestima suočavaju i sa duhovnim pripremanjem za nadolazeću smrt, te prema njoj ostvaruju miran i prijateljski stav, prihvatajući je kao jedini svoj izlaz iz života punog patnje i jedinu mogućnost za ostvarenje njihovih težnji (Cesar 1990: 155). Malčikina smrt, kojom roman završava, predstavlja stoga neki vid uznesenja, prihvatanja Hrista za svog mladoženju i saputnika u zagrobnom, po hrišćanskoj eshatološkoj viziji boljem i svetlijem životu od onog koji iza sebe ostavlja.

\section{Zaključak}

Specifična infantilna percepcija sveta u Cankarevom romanu Kuća Marije pomoćnice ogleda se u odnosu dece, kao glavnih aktera, prema osnovnim egzistencijalnim pitanjima života, smrti, slobode, spasenja. Neočekivani pesimizam koji dominira tokom celog romana začudan je stoga što nije u konvencionalnom smislu vezan za pojam deteta i dečijeg, te je ovaj rad zasnovan upravo na pokušaju da se pronađe motivacija za takav Cankarev postupak.

Počevši od šireg, prostornog i vremenskog, plana romana, na idejnom i semantičkom polju uočavaju se određeni motivi koji konstituišu negatvnu sliku sveta. Naime, deca koja žive u bolnici odbačena su od strane svojih porodica, marginalizovana u odnosu na ostatak sveta, te im jedino preostaje da prihvate turoban način života koji im je nametnut. Život i sloboda u takvom stanju stvari nemaju za njih pozitivne vrednosti, što dovodi do toga da se devojčice priklone smrti i sa nestr- 
pljenjem je iščekuju kao svoje izbavljenje. Kontinuitet naracije donekle je očuvan postavljanjem Malčikine priče za nukleus pripovedanja, međutim, simboličke epizode, kao i brojne retrospekcije, sa jedne strane narušavaju kontinuitet pripovedanja, ali sa druge strane doprinose psihološkoj karakterizaciji likova i motivaciji njihovih postupaka i načina mišljenja. Osvetljavanjem brojnih trauma od kojih devojčice pate usled neadekvatnog odrastanja, otvara se mnoštvo motiva koji omogućavaju povezivanje teme infantilne percepcije sveta sa porodičnim modelom sa jedne strane, ali i sa hrišćanskim slojem romana sa druge strane. Naime, kao posledica nezdrave sredine u kojoj su odrastale, devojčice u bolnici pate od neizlečivih bolesti fizičke prirode, ali i trauma na emotivno - psihološkom planu. Sa druge strane svet izvan bolnice, u koji spada i porodični prostor iz kojeg su potekle, devojčice karakterišu kao moralno nečist, licemeran, pun zlobe. Stoga se može uočiti jasan kontrast koji se između devojčica i njihovih porodica, a onda i ostatka sveta, konstituiše. Uključivanjem religijskog sloja romana i direktnom paralelom devojčica sa Hristom kao univerzalnim simbolom žrtve, pesimistična vizija sveta koja se u romanu javlja može se motivisati na podlozi naturalističkog nasleđa koje Cankar unekoliko baštini u ovom romanu, istovremeno ga upotpunjući modernism poetičkim tendencijama. Stoga se na kraju može izvesti zaključak da je specifična infantilna percepcija sveta u Cankarevom romanu Kuća Marije pomoćnice konstituisana postavljanjem deteta u položaj stradanja i patnje kako bi na sebe preuzelo žrtvu i svojom smrću koju željno iščekuje okajalo grehe porodičnog okrilja iz kojeg potiče.

\section{Literatura}

Ivan CANKAR, 1956: Eseji, kritike i feljtoni. Beograd: Prosveta

Ivan CESAR, 1990: Od riječi do znaka. Zagreb: Globus.

Janko KOS, 1975: Pregled slovenskega slovstva. Ljubljana: Državna založba Slovenije.

Marija MITROVIĆ, 1995: Pregled slovenačke književnosti. Sremski Karlovci: Izdavačka knjižarnica Zorana Stojanovića.

Иван ЦАНКАР, 1964: Дом Марије Помоћнице у: Вињете. Београд: Нолит 


\title{
CHILD'S PERCEPTION OF THE WORLD IN IVAN CANKAR'S NOVEL KUĆA MARIJE POMOĆNICE THE WARD OF OUR LADY OF MERCY
}

\begin{abstract}
Summary:
Cankar's novel The Ward of Our Lady of Mercy published in 1904 represents an important step towards modern literature with indepth psychological dimensions of the characters as well as with a developed symbolic layer of a story about marginalized girls. Third person narrator guided by Malči gives the readers insight into the marginalized convent/hospital that functions by its internal logic that overcomes the convencional horizon of expectation. Cold and dark enterier of the hospital is inhabited by children which in a reader activates a string of associations related to the concepts of innocence, vitalism and joyfulness. However, semantic solutions brought by the novel conflict with given concepts. Therefore the reader encounters a whole array of children's feelings, thoughts and conversations that aren't inherent to them. That's why this paper focuses on the naturalism heritage Cankar uses in this novel in order to try to motivate childs suffering and disdain towards life and its positive values related to sins of their parents. On the other hand the religious layer of the novel contributes to the constructing of the victim motif, that fits into expiation narrative and the hope for the better life after death.
\end{abstract}

Key words: child, life, death, sickness, family, Cankar 